\title{
Chlorophyll Fluorescence Analysis and Imaging in Plant Stress and Disease
}

\author{
P.F. Daley
}

This paper was prepared for submittal to the 6th International Congress of Plant Pathology Montreal, Canada

July 28-August 6, 1993

December 1994

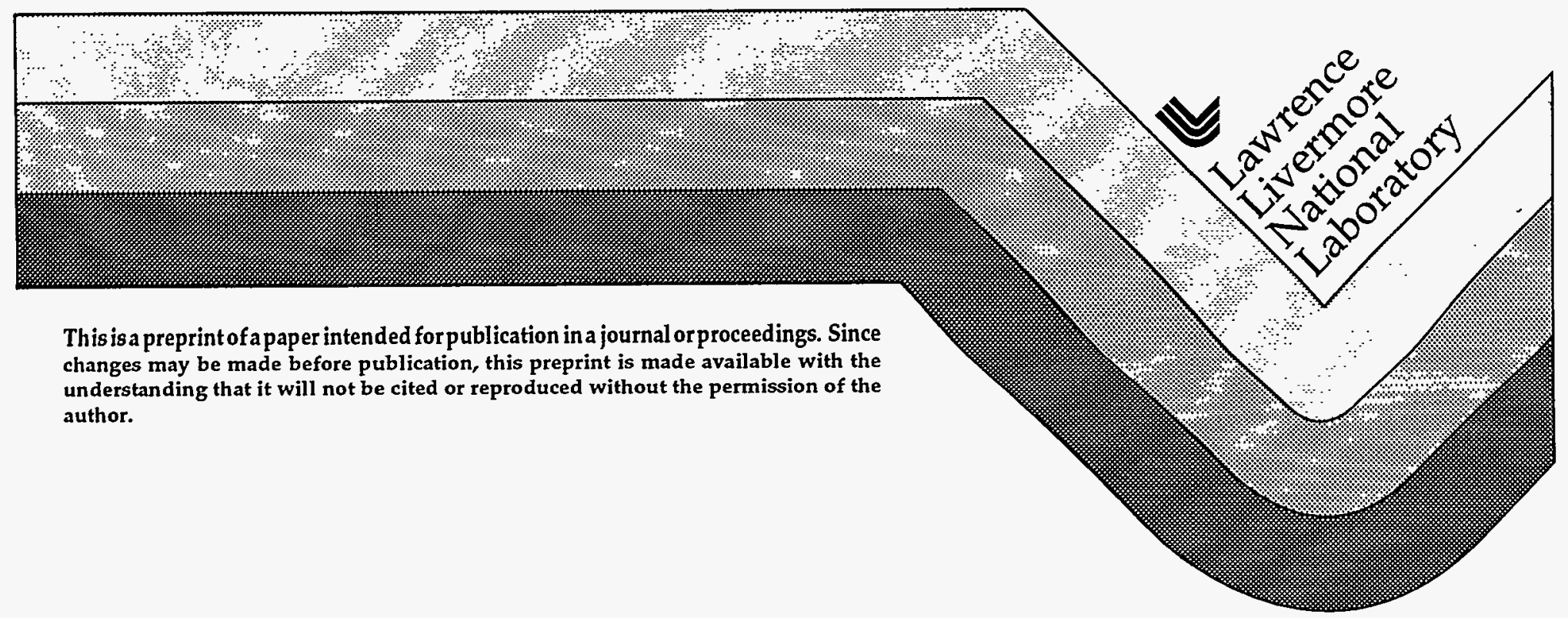




\section{DISCLAIMER}

This document was prepared as an account of work sponsored by an ageacy of the United States Government. Neither the United States Government nor the University of California nor any of their employees, makes any warranty, express or implied, or assumes anylegal liability or responsibility for the accuracy, completeness, or usefulness of any information, apparatus, produch, or process disdosed, or represents that its use would dnot infringe privately owned rights. Reference herein to any specific commercial products, process, or service by trade name, trademark, manufacturer, or otherwise, does not necessarily constitute or imply its endorsement, recommendation, or favoring by the United States Government or the University of Califorria. The views and opinions of authors expressed herein do not necessarily state or reflect those of the United States Government or the University of Califomia, and shall not be used for advertising or product endorsement purposes. 


\section{DISCLAIMER}

Portions of this document may be illegible in electronic image products. Images are produced from the best available original document. 


\title{
Chlorophyll fluorescence analysis and imaging in plant stress and disease
}

\author{
Paul F. Daley \\ Environmental Restoration Division \\ Lawrence Livermore National Laboratory \\ P.O. Box 808 / L-528; Livermore, CA, USA 94550 \\ Initernet: daley1@llnl.gov.
}

This paper is part of a collection of contributions on epidemiology, crop loss assessment, and phytopathometry that were presented in symposia and discussion sessions at the Sixth International Congress of Plant Pathology, Montréal, Québec, Canada, July 28-August 6, 1993. 
Quantitative analysis of chlorophyll fluorescence transients and quenching has evolved rapidly in the last decade. Instrumentation capable of fluorescence detection in bright actinic light has been used in conjunction with gas exchange analysis to build an empirical foundation relating quenching parameters to photosynthetic electron transport, the state of the photoapparatus, and carbon fixation. We have developed several instruments that collect video images of chlorophyll fluorescence. Digitized versions of these images can be manipulated as numerical data arrays, supporting generation of quenching maps that represent the spatial distribution of photosynthetic activity in leaves. We have applied this technology to analysis of fluorescence quenching during application of stress hormones, herbicides, physical stresses including drought and sudden changes in humidity of the atmosphere surrounding leaves, and during stomatal oscillations in high $\mathrm{CO}_{2}$. We describe a recently completed portable fluorescence imaging system utilizing LED illumination and a consumer-grade camcorder, that will be used in long-term, non-destructive field studies of plant virus infections. 
In recent years, chlorophyll (Chl) fluorescence has become an increasingly useful means for determining the energy state of the photosynthetic apparatus (6, $17,21,23,29$ ) of plants, particularly in studies on environmental influences such as adaptation to light, extremes of temperature, drought, exposure to chemical agents or UV-B radiation, and disease $(2,9,16,18,26,27,28,31)$. This has been stimulated by improvements in methods for Chl fluorometry and our understanding of the mechanisms competing for the excitation energy trapped by photosynthetic systems. This paper describes the development of a quantitative approach to analyze spatial components of fluorescence emissions from leaves through the use of digital imaging. Recent reviews have examined the historical development of Chl fluorescence analysis $(14,17,29)$, and methods of conventional fluorescence recording $(15,23)$. Reports of practical applications in limnology, forestry and agronomy are increasing in number $(16,17,18,26)$, and interest is mounting in the exploitation of remote fluorescence sensing $(10,16)$, as a "ground-truthing" technique to augment other forms of remote sensing.

Modulated light Chl fluorometers often "view" the leaf with non-imaging fiberoptic bundles, and average information over one to several square centimeters of leaf surface $(25,26)$. However, the discrete compartments defined by the leaf vasculature in many species of herbaceous plants and deciduous trees are much smaller than this. These compartments may isolate regions with distinct characteristics, such as stomatal diffusivity or degree of infection by a pathogen that could, in turn, create a mosaic of biochemical activity. This greatly complicates biochemical interpretation of gas-exchange from photosynthesis under stress conditions. We hypothesized that, if present, this heterogeneity would modulate fluorescence yield, and that differences might be sufficient to discriminate by digital imaging techniques. We have prepared images of nonphotochemical quenching $\left(q_{N}\right)$ from video images of leaf fluorescence (8), and from these, derived images in which grey-levels represent the underlying rate of photosynthesis (7). In numerous cases the apparent photosynthetic activity was markedly non-uniform. 


\section{Fluorescence analysis and imaging techniques}

- Upon illumination, the fluorescence yield of dark-adapted leaves rises rapidly (200-500 ms) to a maximum (dark-adapted maximum fluorescence, $\left(F_{M}\right)_{D}$ or maximum variable fluorescence, $\left.\left(\mathrm{FV}_{\mathrm{V}}\right)_{\mathrm{M}}\right)$ and then falls, sometimes in an oscillating manner (variable fluorescence, $\mathrm{F}_{\mathrm{V}}$ ), as photosynthesis and fluorescence yield both approach a steady state $(6,14,21)$. Bright flashes of light $\left(3-4000 \mu \mathrm{E} \cdot \mathrm{m}^{2} \cdot \mathrm{s}^{-1}\right)$ delivered during the variable fluorescence yield phase produce a yield is referred to as saturated variable fluorescence, $\left(F_{V}\right)_{S}$. Analysis of the kinetics of this phenomenon, known as the Kautsky effect (13), was well established by the time more advanced instruments permitted detailed examination of the mechanisms that modulate fluorescence yield $(5,11)$. Some commercial fluorometers measure a very rapid transition in fluorescence excited only by a weak, modulated-light measuring beam $\left(F_{0} ; 25,26\right)$. $F_{0}$ has been reported to be useful for analysis of stress responses (26), but this transition is so rapid $(<0.5 \mathrm{~ms})$ that it cannot be resolved by conventional video framing rates $(\sim 16 \mathrm{~ms})$. We will not address video methods for $F_{o}$ estimation.

Decline in fluorescence yield from maximum levels is generally referred to as quenching, and is caused by a suite of mechanisms that includes primary photochemical quenching ( $q_{Q}$, associated with trapping of quanta and water splitting by photosystem II [LHCII]), and other secondary processes that appear to collectively drain excess excitation energy away from the reaction centers (nonphotochemical quenching, $q_{N}$ ). These parameters can be estimated from fluorescence yield data (Fig. 1). Non-photochemical fluorescence quenching is correlated with the establishment of proton gradients between the different compartments of the chloroplast, that in turn may drive reversible synthesis of xanthophyll pigments, particularly zeaxanthin. Zeaxanthin formation may be responsible for quenching by resonant energy transfer (9). Other components of $q_{N}$ include changes in the distribution of LHCII complexes; recent work points to functional linkages between these processes (24). $q_{N}$ is measured during experiments in which the yield of fluorescence is recorded during light flashes that saturate the photoapparatus $\left(3-5000 \mu \mathrm{E} \cdot \mathrm{m}^{2} \cdot \mathrm{s}^{-1} ; 5,25\right)$. If photosysnthesis is simultaneously measured by gas-exchange analysis, an empirical correlation can be 
developed to predict photosynthetic activity under a broad range of conditions, based on parameters derived from fluorescence (32).

Imaging of whole-leaf Chl fluorescence has been achieved with a phosphoroscope and photography (4) and with video cameras (19). We have developed a series of bench top systems for imaging in a macro-photographic range of magnifications (Fig. 2), in order to resolve fluorescence emissions in the areoles of heterobaric leaves exposed to abscisic acid ( $A B A ; 8,30)$. Fluorescence excitation was accomplished with argon-ion lasers, continuous-burn xenon lamps, or fiber-optic illuminators using halogen lamps $(7,8)$. Light intensity was controlled with shutters or with filter wheels. Emissions were detected with monochrome or color charge-coupled device (CCD) cameras equipped with macro lenses and band-pass or long-pass filters in the 695-740 nm region (most CCD cameras are equipped with far-red filters that block beyond $690 \mathrm{~nm}$, that must be removed for fluorescence imaging). In all cases the cameras had to be set for manual control of gain. Video signals were recorded on conventional analog videotape for later processing, or immediately captured (digitized) with "framegrabber" boards for microcomputers.

We have more recently built a portable system based on a consumer grade Hi8 camcorder (S-video capable, 8-mm format; Canon L-1), and an illuminator utilizing a conical array of ultrabright red light-emitting diodes (LEDs; AND, Inc., Burlingame, California) with primary emission at $660 \mathrm{~nm}$ (Fig. 3). With twelve LED beams crossing in a $-2 \mathrm{~cm}$ diameter spot, plant tissues are uniformly illuminated with saturating pulses of actinic (steady state) illumination, with intensity up to $4000 \mu \mathrm{E} \cdot \mathrm{m}^{2} \cdot \mathrm{s}^{-1}$. Precision of the light output is better than $2 \%$. This system also includes an embedded single-board computer (Z-World Engineering, Davis, California), which controls both the LED array, and the camera via a serial interface (control-L or LANC; Sony, Inc.). Dark-adaptation of leaves in the field is accomplished with shuttered leaf clips developed for a portable, commercial fluorometer (Plant efficiency analyzer, PEA; Hansatech Instruments, Ltd., King's Lynn, Norfolk, UK). A detailed analysis of the performance of this portable system is in preparation. 
Once images from any of these systems are digitized, each pixel is normalized against a frame taken during $\left(\mathrm{FV}_{\mathrm{M}}\right.$, using an arithmetic scheme adapted from Schreiber $(25,26)$. Frames representing any of the derived fluorescence parameters in the grey-scale (e.g.: $q, q_{N}, q_{Q}$ ) can be prepared by appropriate manipulations of frames acquired during $F_{V}$ or $\left(F_{V}\right)_{S}$, and the reference, $\left(F_{V}\right)_{M}$. Using this approach in parallel with an area-averaging system (PAM, Heinz Walz NA, FRG), a high correlation between $C C D$ detection and conventional modulatedlight fluorometers can be demonstrated (8; Fig 4).

In our original work (8), additional steps were required to properly scale the resulting values, owing to the lack of floating-point subsystems on the minicomputer used for processing. Since that time, software libraries have become available that support floating-point arithmetic processors on desktop microcomputers, in a graphical programming environment (Concept VI, Graftek, France; LabVIEW, National Instruments, Austin, Texas) that greatly facilitates development of custom image acquisition and analysis applications.

The derived images can be subjected to a variety of analyses or calibration operations particularly if imaging of non-stressed control leaves can be performed along with gas exchange analysis (12). This supports estimation of $\mathrm{c}_{\mathrm{i}}$ (mesophyll CO2 concentration) or photosynthesis rate on an area resolved basis during imposition of stress or disease (7).

\section{Applications to Plant Stress and Disease}

Many plant pathogens cause obvious damage to photosynthetic tissues, as evidenced by lesions, chlorosis or diminished yield. It has been suggested that viruses such as tobacco mosaic virus (TMV) may be viewed as parasites of chloroplasts (3), and that they compete for nitrogen reserves otherwise utilized in the synthesis of ribulose 1,5-bisphosphate carboxylase (rubisco). This may also be true for a variety of other viral pathogens (22). Time course studies of these infections or their distribution within plants or communities is hampered by the labor intensive nature of virus isolation and characterization. Moreover, some virus infections may not be accompanied by visible symptoms, or symptoms may 
develop only when the host is placed in an environment that places increased demands on scarce resources (20). We have observed that some virus strains may reduce photosynthesis, and cause patchy fluorescence quenching in host leaves, well before lesions become visible to the eye (20). We are planning experiments to evaluate the portable fluorescence imaging system for determining virus distributions within and between plants, through seasons and across different habitats.

Several examples of fluorescence images following experimentally applied stress (ABA, herbicides) have been reported previously $(7,8)$. We have also observed dramatic spatial variation in fluorescence quenching of low-light adapted tobacco leaves with moderate nitrogen stress, during stomatal oscillations.

Oscillations were induced by placing a leaf in a dark, high $\mathrm{CO}_{2}$ atmosphere ( $>2500$ $\left.\mu 1 \cdot \mathrm{I}^{-1}\right)$ for $10 \mathrm{~min}$ then illuminating in continuous high light $\left(\sim 2000 \mu \mathrm{E} \cdot \mathrm{m}^{2} \cdot \mathrm{s}^{-1}\right)$ for a 5-min recording period; images were recorded at 5-sec intervals. In this experiment, no saturating flashes were applied, but $F_{V}$ images were normalized against a frame taken at $\left(\mathrm{FV}_{\mathrm{V}}\right)_{\mathrm{M}}$, to generate images of total quenching, $q$. Fig. 5 illustrates a trace from an area averaging fluorometer trained on the leaf; Fig. 6 shows this same trace with four frames selected from the image sequence at various times, along with surface plots of the $q$ quenching frames (plots were generated using Transform 2.1, Spyglass, Inc., Champaign-Urbana, Illinois).

During the first $1.5 \mathrm{~min}$, the overall fluorescence emission oscillated strongly, but was relatively uniform across the leaf surface (Frame 1). However, as the "primary" oscillation dampened, spatial oscillation was observed. This appeared as fronts of alternating quenching and relaxation (markedly higher in fluorescence yield) moving across the leaf. In many instances these fronts originated along veins, particularly near branch points in the vein structure (cf: Frame 25). Late in the experiment, when oscillation was no longer observable by the area-averaging fluorometer, a highly localized region of relaxed quenching emerged from a vein branch point (top center, Frame 53). This front of relaxed quenching migrated across the leaf for approximately the last $30 \mathrm{sec}$ of the experiment (Frame 60). 
The velocity and spatial aspect of this migrating region was striking, and reminiscent of dispersion of applied $A B A$ in earlier experiments (8), although the trend during $\mathrm{ABA}$ application was always toward increased quenching and diminished gas exchange, but here there were oscillations above and below local average quenching levels. With the small regions involved, and speed of the response, a mechanistic explanation of this phenomenon will admittedly be difficult to develop.

\section{Conclusions}

Chl fluorescence imaging is a direct outgrowth of conventional fluorescence analysis, that can be shown to produce grey-scale images in which the values quantitatively represent the level of quenching attributable to photochemistry or "photoprotective" non-photochemical energy dissipation (24). Equipment required to produce these images is now modest in cost, and both capture and analysis of digital images can be performed easily with desktop microcomputers. Analysis of quenching kinetics from small regions is useful in addressing the distribution of photosynthesis activity across the surface of leaves, and can detect changes in the behavior of regions where virus infections have occured (1), well before visible lesions have developed. In some cases, infections by low-virulence virus strains, that impaired photosynthesis but did not produce lesions, have been visualized with the imaging technique (20). Application of this approach to "scouting" for other plant stresses and disease agents may be possible with portable imaging systems now under development.

One possible drawback to the technique is the dependence on computer processing. Image processing is, in general, a memory and storage intensive operation. We typically store images only one quarter the size of typical displays ( $320 \times 240$ pixels), yet a 60 frame experiment such as that excerpted in Fig. 6 occupies about 4.6 megabytes on disk. Animating a dataset of these images produces a dramatic presentation that readily reveals subtle changes taking place during experiments, but for best performance animation requires holding all the 
images in memory. Fortunately the rapid expansion of microcomputer capabilities . has outpaced the emerging demands of fluorescence imaging.

\section{Acknowledgements}

The author gratefully ackowledges the encouragement, suggestions and support of Drs. C.B. Osmond, J. A. Berry, K. Raschke, S. Robinson and S. Balachandran. This work was supported in part by NSF grant BSR 891451.

This work was performed under the auspices of the U.S. Dept. of Energy at LLNL under contract no. W-7405-Eng-48. 


\section{LITERATURE CITED}

1. Balachandran, S., C.B. Osmond and P.F. Daley. 1994. Diagnosis of the earliest strain-specific interactions between tobacco mosaic virus and chloroplasts of tobacco leaves in vivo by means of chlorophyll fluorescence imaging. Plant Physiol. 104:1059-1065.

2. Banninger, C. 1993. Fluorescence measurements of Norway spruce needles for detecting toxic concentrations of heavy metals in the soil substrate. Pages 111-115 in Proceedings of the Ninth Thematic Conference on Geologic Remote Sensing, 8-11 February, 1993, Pasadena, California. Environmental Research Institute of Michigan, Ann Arbor, Michigan.

3. Bedbrook, J.R. and R.E.F. Matthews. 1973. Changes in the flow of early products of photosynthetic carbon fixation associated with replication of TYMV. Virology 53:84-91.

4. Bjorn, L.O. and A.S. Forsberg. 1979. Imaging by delayed light emission (phytoluminography) as a method for detecting damage to the photosynthetic system. Physiol. Plant. 47:215-222.

5. Bradbury, M. and N.R. Baker. 1981. Analysis of the slow phases of the in vivo chlorophyll induction curve. Changes in the redox state of photosystem II electron acceptors and fluorescence emission from photosystem I and II. Biochim. Biophys. Acta 63:542-551.

6. Briantais, J.-M., C. Vernotte, G.H. Krause and E. Weis. 1986. Chlorophyll $a$ fluorescence of higher plants: chloroplasts and leaves. Pages 539-583 in Govindjee, J. Amesz and D.C. Fork, eds., Light Emission by Plants and Bacteria, Acad. Press, Orlando, Florida.

7. Daley, P.F., J.T. Ball, J.A. Berry, J. Patzke and K. Raschke. 1990. Visualizing photosynthesis through processing of chlorophyll fluorescence images. Pages 243-249 in A.C. Bovik and W.E. Higgins, eds., Biomedical Image Processing, Proc. SPIE 1245. SPIE, Bellingham, Washington. 
8. Daley, P.F., K. Raschke, J.T. Ball and J.A. Berry. 1989.

Topography of photosynthetic activity of leaves obtained from video images of chlorophyll fluorescence. Plant Physiol. 90:1233-1238.

9. Demmig, B., K. Winter, A. Krüger and F-C Czygan. 1987. Photoinhibition and zeaxanthin formation in intact leaves. A possible role of the xanthophyll cycle in the dissipation of excess light energy. Plant Physiol. 84:218-224.

10. Doerffer, R. 1988. Remote sensing of sunlight induced phytoplankton fluorescence. Pages 269-274 in H.K. Lichtenthaler, ed., Applications of Chlorophyll Fluorescence, Kluwer Academic Publishers.

11. Duysens, L.N.M. and H.E. Sweers. 1963. Mechanism of two photochemical reactions in algae as studied by means of fluorescence. Pages 353-372 in Jap. Soc. Plant Physiol., eds., Studies on Microalgae and Photosynthetic Bacteria, Univ. of Tokyo Press, Tokyo.

12. Field, C., J.A. Berry and H.A. Mooney. 1982. A portable system for measuring carbon dioxide and water vapour exchange of leaves. Plant, Cell and Environment 5:179-186.

13. Kautsky, H. and A. Hirsch. 1934. Das Fluoreszenverhalten grüner Pflanzen. Biochem Z. 274:422-434.

14. Krause, G.H. and E. Weis. 1991. Chlorophyll fluorescence and photosynthesis: the basics. Ann. Rev. Plant Physiol. Plant Mol. Biol. 42:313-349.

15. Lavorel, J., J. Breton and M. Lutz. 1986. Methodological principles of measurement of light emitted by photosynthetic systems. Pages 58-99 in Govindjee, J. Amesz and D.C. Fork, eds., Light Emission by Plants and Bacteria, Acad. Press, Orlando, Florida.

16. Lichtenthaler, H.K. 1988. In vivo chlorophyll fluorescence as a tool for stress detection in plants. Pages 129-142 in H.K. Lichtenthaler, ed., Applications of Chlorophyll Fluorescence, Kluwer Academic Publishers.

17. Lichtenthaler, H.K. 1988. Remote sensing of chlorophyll fluorescence in oceanography and in terrestrial vegetation: an introduction. Pages 287-297 
in H.K. Lichtenthaler, ed., Applications of Chlorophyll Fluorescence, Kluwer Academic Publishers.

18. MacRae, E.A., A.K. Hardacre and I.B. Ferguson. 1986.

Comparison of chlorophyll fluorescence with several other techniques used to assess chilling sensitivity in plants. Physiol. Plant. 67:659-665.

19. Omasa, K., K.-I. Shimazaki, I. Aiga, W. Larcher, M. Onoe. 1987. Image analysis of chlorophyll fluorescence transients for diagnosing the photosynthetic system of attached leaves. Plant Physiol. 84:748-752.

20. Osmond, C.B., J.A. Berry, S. Balachandran, C. BüchenOsmond, P.F. Daley and R.A.J. Hodgson. 1990. Potential consequences of virus infection for shade-sun acclimation of leaves. Bot. Acta 103:226-229.

21. Papageorgiou, G. 1975. Chlorophyll fluorescence: An intrinsic probe of photosynthesis. Pages 319-371 in Govindjee, ed., Bioenergetics of Photosynthesis, Academic Press, New York.

22. Reinero, A. and R.N. Beachy. 1989. Reduced Photosystem II activity and accumulation of viral coat protein in chloroplasts of leaves infected with tobacco mosaic virus. Plant Physiol. 89:111-116.

23. Renger, G. and U. Schreiber. 1986. Practical applications of fluorometric methods to algae and higher plant research. Pages 587-619 in Govindjee, J. Amesz and D.C. Fork, eds., Light Emission by Plants and Bacteria, Acad. Press, Orlando, Florida.

24. Ruban, A.V., A.J. Young and P. Horton. 1993. Induction of nonphotochemical energy dissipation and absorbance changes in leaves. Evidence for changes in the state of the light-harvesting system of Photosystem II in vivo. Plant Physiol. 102:741-750.

25. Schreiber, U., U. Schliwa and W. Bilger. 1986. Continuous recording of photochemical and non-photochemical chlorophyll fluorescence quenching with a new type of modulation fluorometer. Photosynth. Res. 10:51-62.

26. Schreiber U. and W. Bilger. 1987. Rapid assessment of stress effects on plant leaves by chlorophyll fluorescence measurements. Pages 27-53 in 
J.D. Tenhunen, F.M. Catarino, O.L. Lange and W.C. Oechel, eds., Plant Response to Stress. Functional Analysis in Mediterranean Ecosystems. NATO ASI Series, Vol G15, Springer-Verlag, Berlin Heidelberg.

27. Schreiber, U. and J.A. Berry. 1977. Heat-induced changes of chlorophyll fluorescence in intact leaves correlated with damage of the photosynthetic apparatus. Planta 136:233-238.

28. Seemann, J.R., J.A. Berry and W.J.S. Downton. 1984.

Photosynthetic response and adaptation to high temperature in desert plants. A comparison of gas exchange and fluorescence methods for studies of thermal tolerance. Plant Physiol. 75:364-368.

29. Sivak, M.N. and D.A. Walker. 1985. Chlorophyll $a$ fluorescence: can it shed light on fundamental questions in photosynthetic carbon dioxide fixation? Plant, Cell and Environment 8:439-448.

30. Terashima, I., S-C Wong, C.B. Osmond and G.D. Farquhar. 1988. Characterization of nonuniform photosynthesis induced by abscisic acid in leaves having diffrent mesophyll anatomies. Plant, Cell and Environment 29:385-394.

31. Tevini, M., P. Grusemann and G. Fieser. 1988. Assessment of UV-B stress by chlorophyll fluorescence analysis. Pages 229-238 in H.K. Lichtenthaler, ed., Applications of Chlorophyll Fluorescence, Kluwer Academic Publishers.

32. Weis, E. and J.A. Berry. 1987. Quantum efficiency of photosystem II in relation to "energy"-dependent quenching of chlorophyll fluorescence. Biochim. Biophys. Acta 894:198-208. 


\section{List of Figures}

Fig 1. Schematic of a chlorophyll fluorescence imaging experiment utilizing the saturating pulse technique. Nomenclature from Schreiber et al. $(25,26)$.

Fig 2. Typical apparatus for laboratory fluorescence imaging. In other configurations the xenon lamp would be replaced by argon-ion lasers or fiber-optic halogen ("cold-source") illuminators. Gas exchange apparatus as in (12).

Fig 3. Illuminator for a prototype portable chlorophyll fluorescence imaging system based on a Hi8 camcorder (Canon L-1).

Fig 4. Relationship between $q_{N}$ derived from CCD images ( $\left.q_{N_{v i d e o}}\right)$ and an area-averaging modulated light fluorometer $\left(q_{N_{W a l}}\right)$. Experimental data from a detached Xanthium strumarium L. leaf, during application of $10^{-4} \mathrm{M}$ abscisic acid to the cut petiole. Illumination with $680 \mu \mathrm{E} \cdot \mathrm{m}^{2} \cdot \mathrm{s}^{-1}$ actinic light, $200 \mu \mathrm{l} \cdot \mathrm{l}^{-1} \mathrm{CO}_{2}, 2 \% \mathrm{O}_{2}, 80 \% \mathrm{RH}$.

Fig 5. Output from an area-averaging fluorometer (Hansatech Instruments, Ltd.) during induction of stomatal oscillation in a low-light adapted tobacco leaf (Nicotiana tobaccum L.). (See Fig. 6).

Fig 6. Average fluorescence yield (line plots), source fluorescence images (center), and surface plots of the intensity of gross fluorescence quenching $(q)$ during stomatal oscillation in a low-light adapted tobacco leaf. Crosshair cursors on the line plots indicate the time location of video frames. The $x$ and $y$ axes of the surface plots are the rows and columns of the digitized image; the $\mathrm{z}$-axis is total quenching, $q$. 


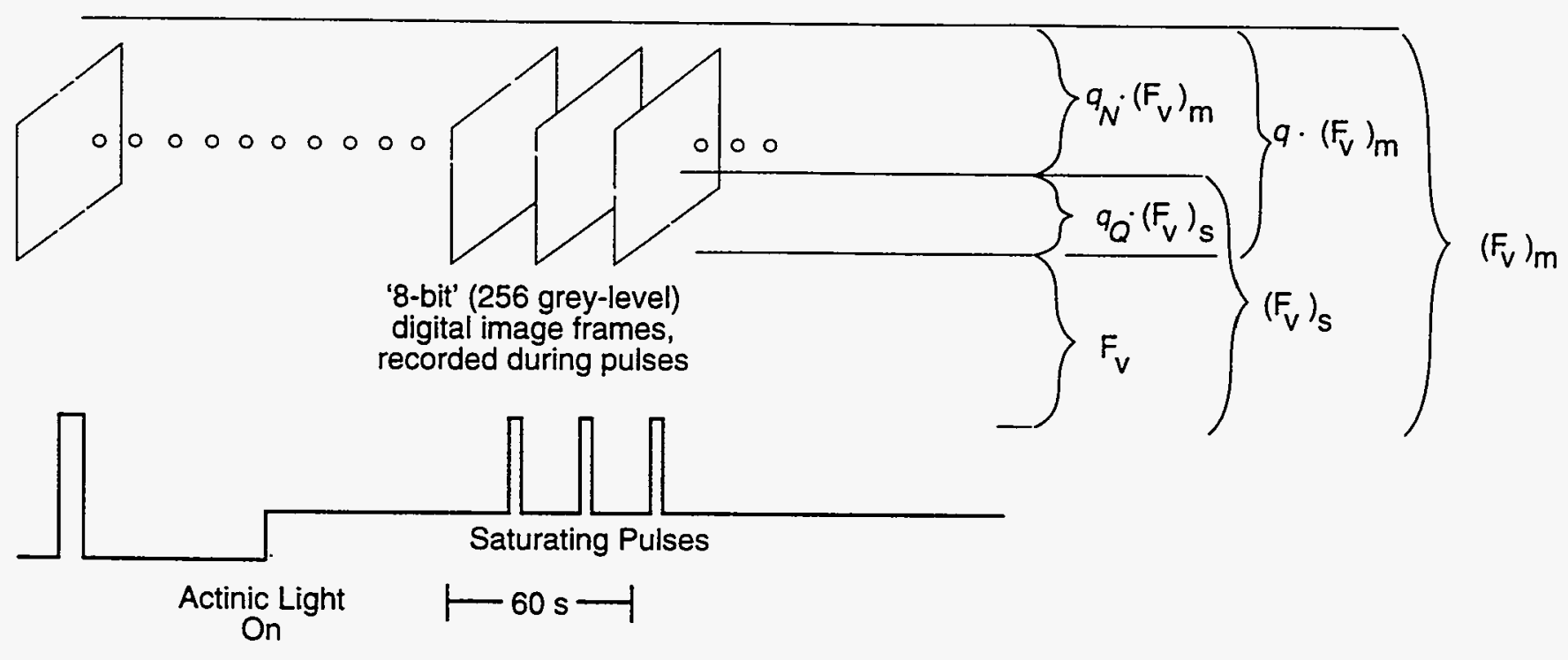

Daley...Figure 1 
Xenon lamp, water filter, colored glass filter, lens, shutter

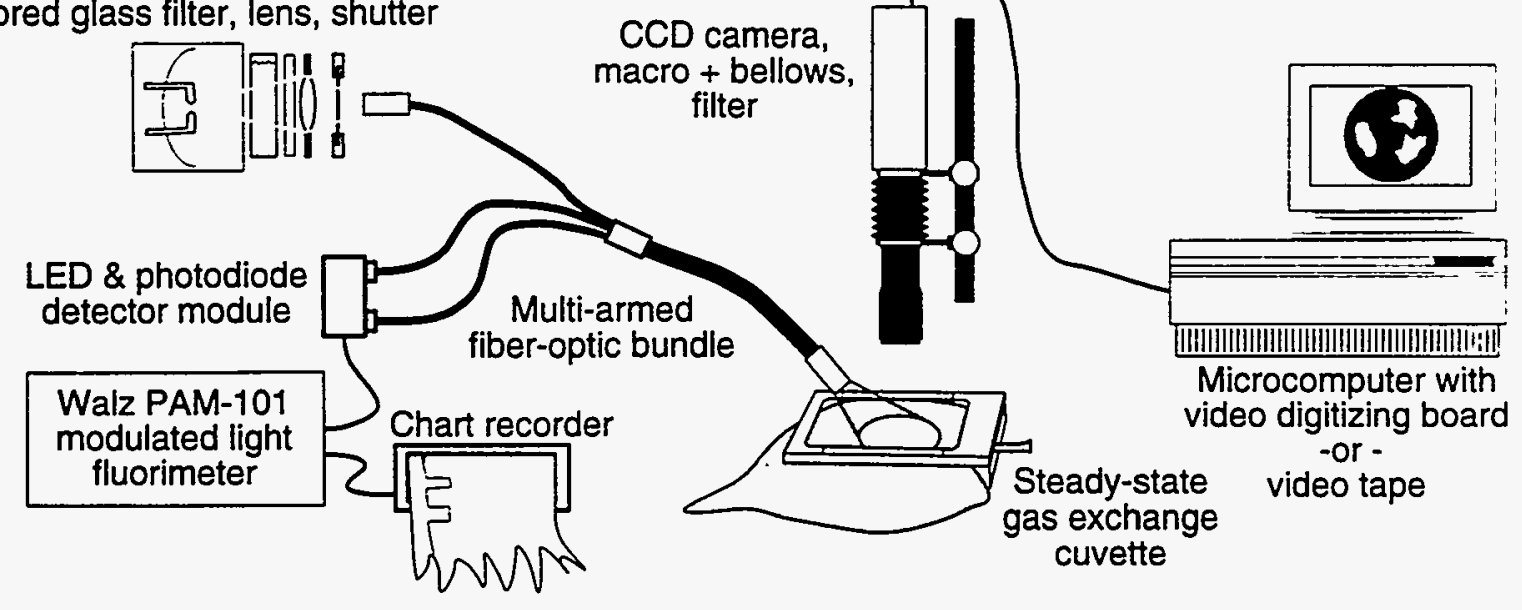




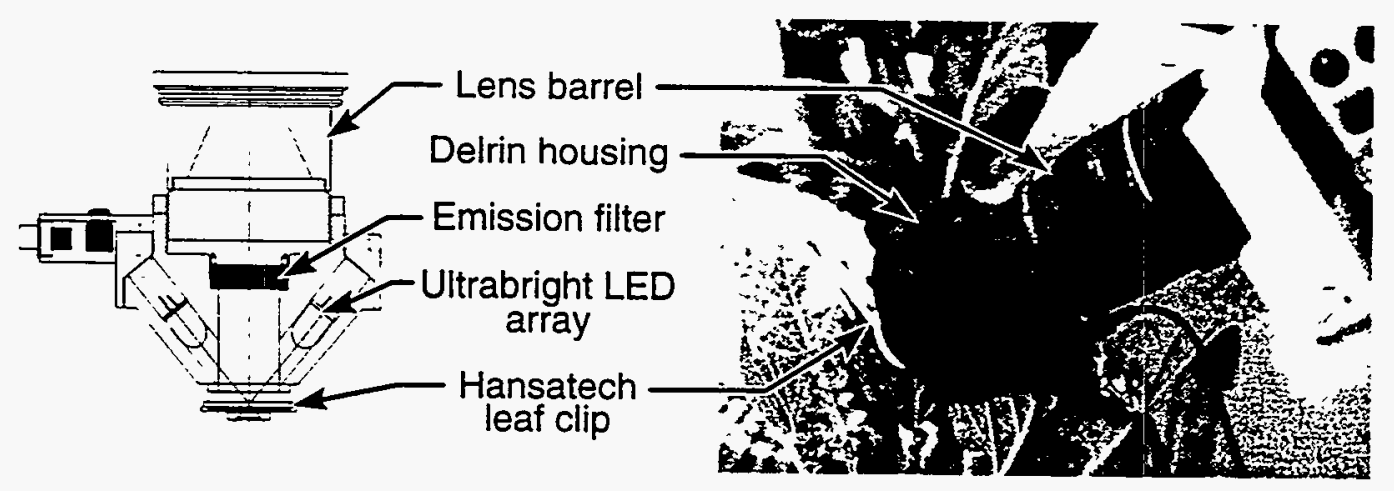




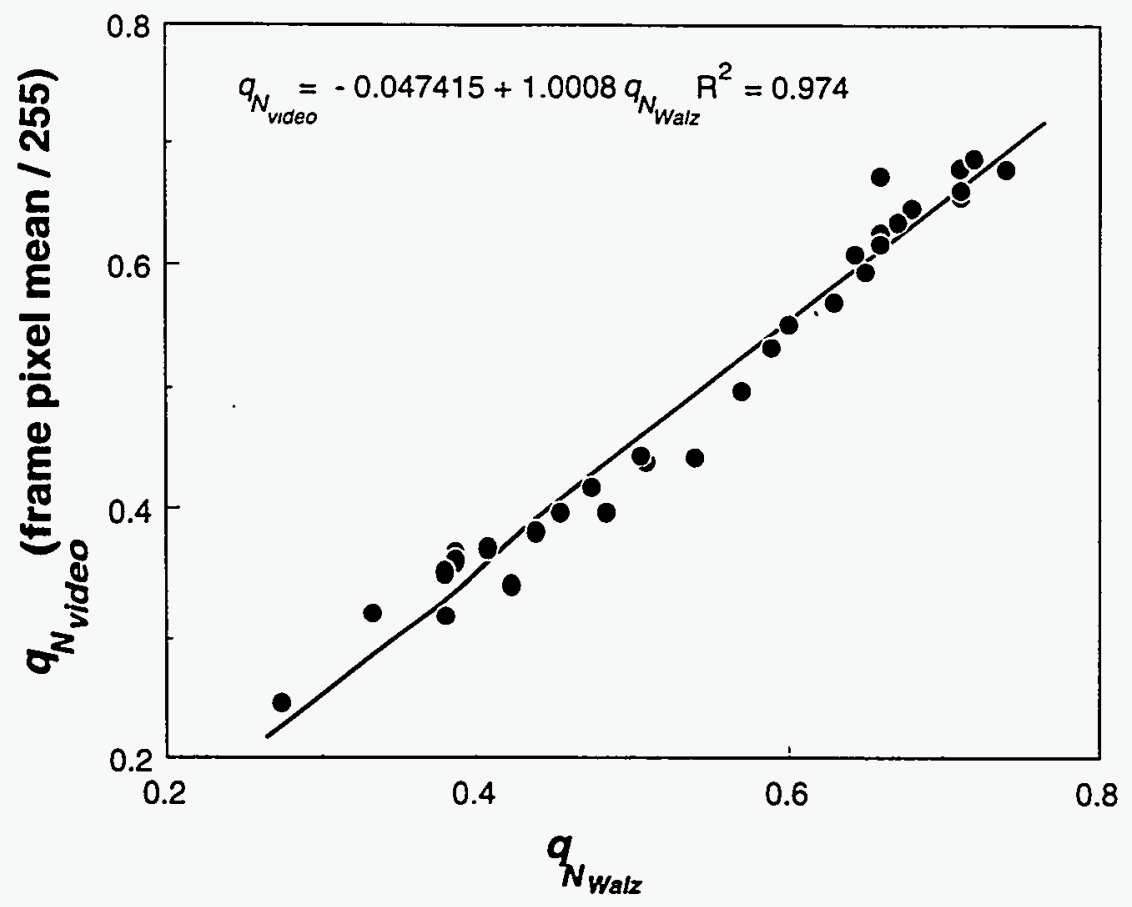

Daley...Figure 4 


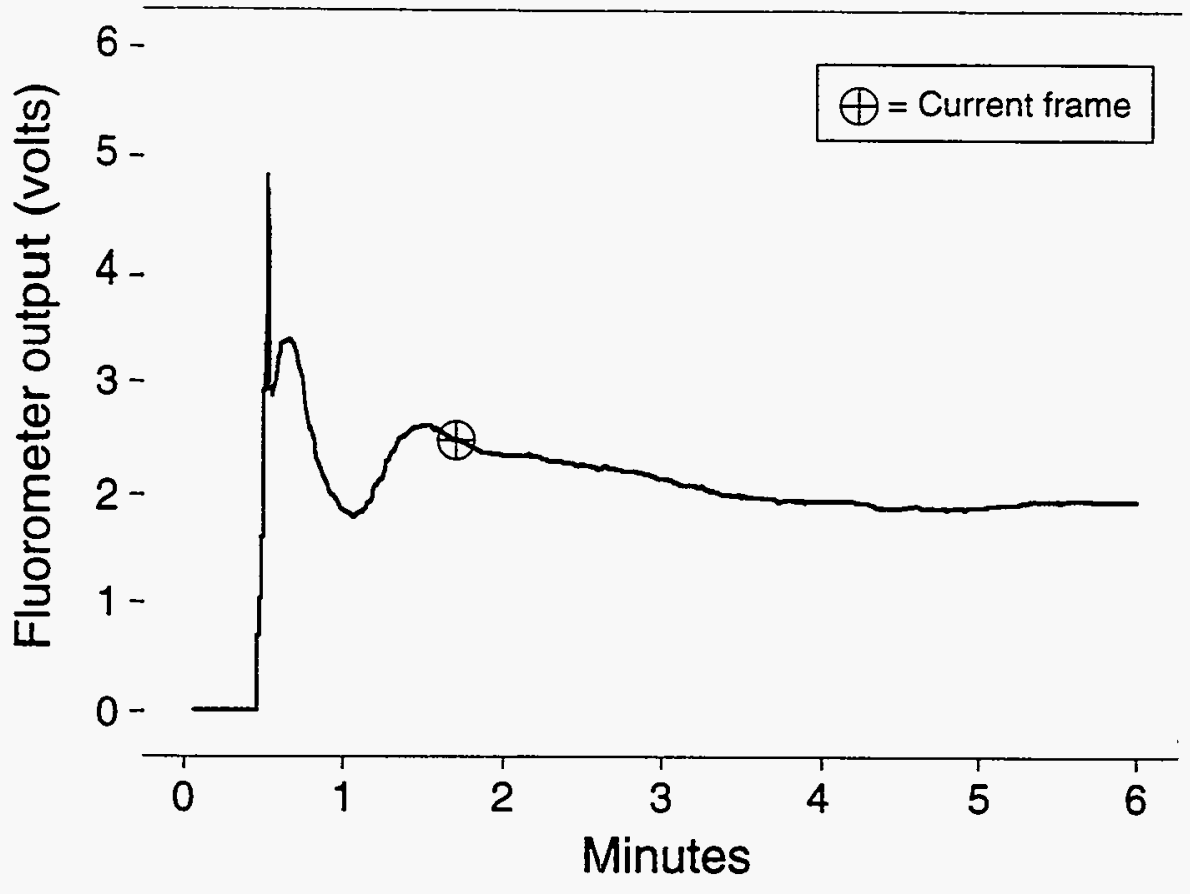

Daley Figure 5 
Frame 1
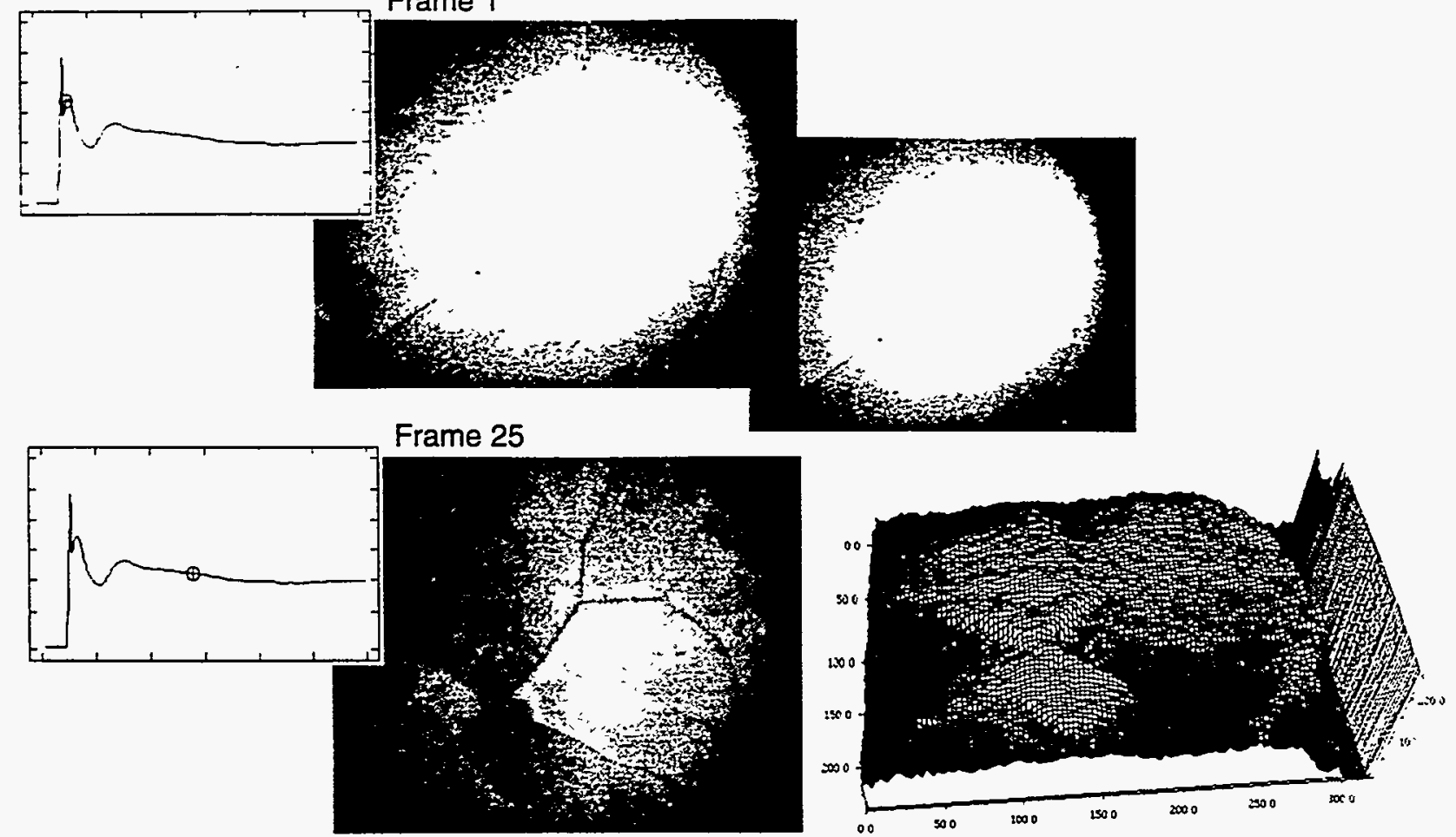

Frame 53
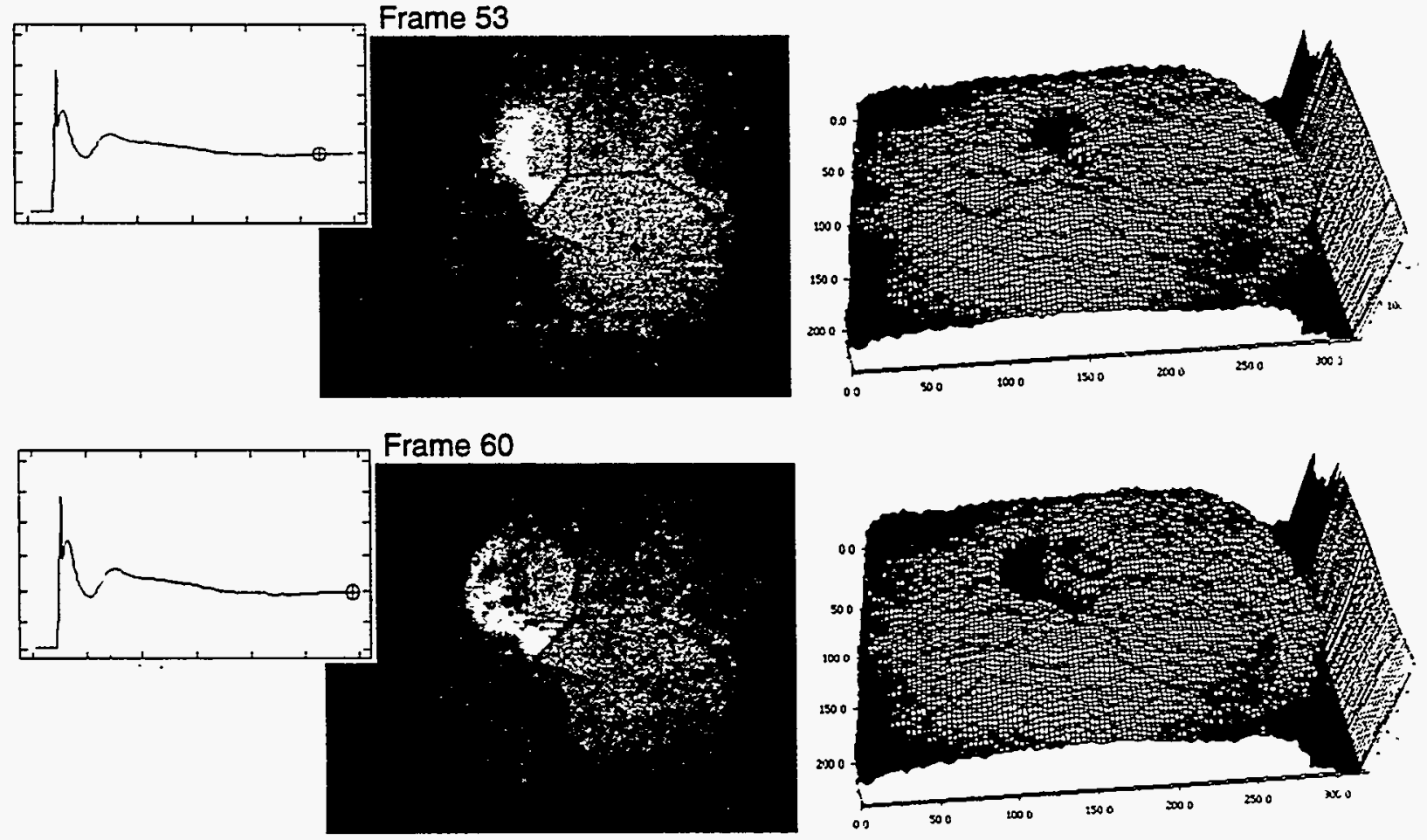

$1 \mathrm{~cm}$

Daley...Fıgure 6 